\title{
IDENTIDADE DO PROFESSOR: UMA RECONCEITUALIZAÇÃO COM BASE NO REFERENCIAL DO EMPODERAMENTO
}

\author{
Manuel Gonçalves Barbosa ${ }^{1}$
}

\begin{abstract}
Resumo
A mera transmissão de conteúdos disciplinares, durante muito tempo porto de abrigo e sinal distintivo do professor, tornou-se problemática e uma via de sentido estreito para definir a identidade desse profissional, especialmente numa altura em que se exige cada vez mais da escola participação ativa no empoderamento dos alunos. É nesse panorama de fundo que se coloca, com alguma premência, a questão da necessária reconceitualização da imagem de marca do professor, e não só por questões de visibilidade e de reconhecimento junto da opinião pública e da comunidade educativa, mas sobretudo porque essa imagem renovada é essencial à definição de um quadro de referência que proporcione modos de ser e fazer a profissão face aos desafios educativos que hoje assediam a escola. O presente texto tem como ponto de amarração essas questões, analisa-as em profundidade à luz de tendências recentes e propõe, de modo inovador, uma nova gramática de ser professor na escola socioeducativa dos nossos dias, mobilizando, para o efeito, o referencial do empoderamento.
\end{abstract}

Palavras-chave: professor; identidade; empoderamento; reconceitualização

\footnotetext{
${ }^{1}$ Doutor em Educação pela Universidade do Minho (Portugal) e Prof. Associado no Instituto de Educação da mesma universidade. Membro do Centro de Investigação em Educação (CIed). E-mail: mbarbosa@ie.uminho.pt
} 


\title{
TEACHER'S IDENTITY: A RECONCEPTUALIZATION BASED ON THE REFERENTIAL OF EMPOWERMENT
}

\begin{abstract}
The mere transmission of subject contents, for a very long time the safe haven and distinctive sign of the teacher, has become problematic and a narrowing path to define the identity of that professional, especially at a time that it is required to school a larger active participation in the empowerment of students. It is in this background panorama that arises, with some urgency, the issue of the necessary reconceptualization of teacher's brand image, and not only for visibility and recognition issues among the public opinion and the educational community, but above all because this renewed image is essential to the definition of a framework that provides ways of being and doing the profession considering the educational challenges that harass school nowadays. This text has these issues as an anchorage point, analyzes them in depth in the light of recent trends and proposes, in an innovative way, a new grammar of being a teacher in the socio-educational school of nowadays, mobilizing, for this purpose, the referential of empowerment.
\end{abstract}

Keywords: teacher; identity; empowerment; reconceptualization

\section{IDENTIDAD DEL PROFESOR: UNA RECONCEPTUALIZACIÓN BASADA EN EL REFERENCIAL DEL EMPODERAMIENTO}

\begin{abstract}
Resumen
La mera transmisión de contenidos disciplinares, por un largo tiempo refugio y signo distintivo del profesor, llegó a ser problemática y además una ruta de sentido estrecho para definir la identidad de este profesional, especialmente cuando se requiere cada vez más participación activa de la escuela en el empoderamiento de los estudiantes. Es en este panorama de fondo que se presenta con cierta urgencia la cuestión de la obligatoria reconceptualización de la imagen de marca del profesor y no sólo por razones de visibilidad y reconocimiento del público y de la comunidad educativa, pero sobre todo
\end{abstract}


porque esa renovada imagen es esencial para definir un marco de referencia que proporciona maneras de ser y hacer la profesión frente a los retos educativos que ahora acosan la escuela. El presente texto tiene como punto de anclaje estos temas, los analiza en profundidad a la luz de las tendencias más recientes y propone, con carácter inovador, una nueva gramática de ser profesor en la escuela socioeducativa de nuestros días, movilizando para ello el referencial del empoderamiento.

Palabras-clave: professor; identidad; empoderamiento; reconceptualización

\section{INTRODUÇÃOO}

A imagem identitária do professor, ao contrário do que afirmam certas posições essencialistas, não é conformada por características fixas e imutáveis. Ser professor é estar sendo, é construir e reconstruir maneiras de ser e estar na profissão num pano de fundo de expectativas sociais, de injunções institucionais e de ideias ou imaginários pessoais. Ser professor é interrogar-se permanentemente sobre o que significa ser professor aqui e agora, é delinear uma imagem quanto ao trabalho que se faz e importa fazer, é estar atento ao que se passa para não ser ultrapassado pelos acontecimentos, é reinventar o modo de ser e de agir quando a mudança se torna inevitável.

Mudanças sociais, culturais e políticas têm tido repercussões no trabalho dos professores e, consequentemente, nas suas identidades profissionais. Aqui, gostaríamos de chamar a atenção para algo que vem de encontro e se encaixa na progressiva acentuação da dimensão social da ação do professor: a preparação do aluno em contextos que, por serem tendencialmente democráticos e aspirarem aos valores da democracia, não toleram, ou toleram cada vez menos, as injustiças sociais e o desrespeito pelos direitos mais fundamentais. Ao trabalhar nestes contextos, a identidade do professor é desafiada a ressignificar-se, a adquirir um outro sentido, um sentido ou significado necessariamente mais social, mais político e também mais moral.

$\mathrm{O}$ que queremos defender, situando nosso argumento na tendência que vem aprofundando a transformação da profissão docente numa prática em que as questões sociais ganham relevância, consiste em admitir que o professor, agente de educação social, precisa de reconfigurar a sua identidade em torno do empoderamento, pela simples razão de ser chamado a reforçar ou a fortalecer as capacidades, ou melhor, os poderes, que fazem 
dos alunos não apenas sujeitos sociais críticos, com uma outra compreensão da realidade, mas também, e sobretudo, atores potenciais da mudança social, intervenientes na transformação de realidades que ferem a dignidade da pessoa humana e negam, no mundo complexo e assimétrico em que vivemos, um futuro democrático para todos.

A identidade profissional do professor está em risco caso se mantenha aferrada à mera transmissão de conhecimentos. A transmissão de conhecimentos, hoje sob a concorrência da Internet, já não chega para fazer a substância da profissão docente. Mais além dessa função, surge (ou ressurge?) a necessidade de educação e, em particular, de educação social, ou seja, a ação que se legitima na preparação dos alunos para viverem como cidadãos no seio dos seus contextos sociais, hoje cada vez mais incertos e problemáticos.

A reconceitualização da identidade do professor em torno do empoderamento visa abrir caminho a uma nova gramática de ser professor na escola de hoje, e é por isso que daremos atenção, na última seção do texto, às várias modalidades de empoderamento que esse profissional da educação e do conhecimento pode realizar em contexto escolar sem sair da cena pedagógica da sala de aula, da sua disciplina ou disciplinas. O objetivo deste texto inscreve-se nessa ideia e desenvolve-se em três momentos: no primeiro, faz-se o mapeamento do terreno de onde se parte, isto é, a análise da mutação da profissão de professor numa tarefa eminentemente social; no segundo, aponta-se para a reconceitualização da identidade do professor desde o empoderamento; no terceiro, por fim, circunscrevem-se as áreas de empoderamento escolar tendo por referência ou marco a preparação do aluno para viver como ator social engajado na construção de um mundo mais conforme às necessidades e às aspirações das pessoas, isto é, mais humano.

\section{MUDANÇAS NA PROFISSÃO DOCENTE: OUTRAS ORIENTAÇÕES, OUTROS VALORES}

Apesar das tendências de sentido contrário, mais por força da imposição de ideologias neoconservadoras do que por pedidos sociais, a escola, enquanto espaço institucionalizado de experiências e de aprendizagens, já não se revê, ou revê-se cada vez menos, numa função ou papel em que as questões sociais e educativas não têm peso, ou se consideram acessórias, secundárias e marginais. A escola agência de educação, incrustada na sociedade, que segue de perto os requerimentos e as problemáticas sociais, nunca 
chegou verdadeiramente a sair de cena, mesmo nos tempos áureos do industrialismo e das políticas de modernização do Estado-nação. O que se pode dizer, olhando a realidade e lendo tendências, é que essa escola está de volta. Vivemos a reemergência da escola educativa, articulada com o devir das questões sociais mais prementes, onde o que importa não é tanto a tarefa instrutiva, de mera transmissão de conteúdos disciplinares, quantas vezes de saberes empacotados prontos a usar em provas de aferição de conhecimentos, mas a função formativa do aluno, da sua realização como pessoa e como cidadão nas arenas da sociedade fluida, complexa, incerta e extremamente dividida quanto a recursos e estatutos.

Esse é um sentido de escola e de experiência escolar que se resgata porque já não é possível fazer de conta que nada se passa na instituição escolar contemporânea: "É uma evidência admitida por todos que, hoje em dia, o sentido da educação em contextos escolares mudou e, com ela, o sentido da escola" (CASTILLO, BRETONES, 2014, p. 26). Ganha relevância ou lugar de destaque a sua função socioeducativa, precisamente numa altura em que se reconhece, desde a análise sociológica da escola, a "erosão da velha clivagem entre educação e instrução" (DUBET, DURU-BELLAT, 2015, p. 46). O que se tem vindo a pedir à escola, pelo menos desde que se tornou omnipresente na vida das crianças e dos jovens e em que a sociedade, ou algumas das suas instituições, como a família, a ela endossaram grande parte da sua função educativa e normativa, é que olhe para a especificidade dos seus públicos e que oriente a sua ação, não tanto pelas disciplinas escolares, mas pela educação dos seus alunos, oferecendo experiências que proporcionem aprendizagens significativas para a vida em sociedade em termos de conhecimentos, atitudes e valores. O ponto focal é o aluno e o seu destino social, num processo complexo e multidimensional em que importa ter em conta, sem descanso e descaso, os contextos de origem e inserção. Trata-se, mais do que nunca, de uma ecologização da instituição escolar ou, o que é o mesmo, de uma ressocialização que tanto abre a escola à sociedade como traz a sociedade para a escola, num movimento de influências mútuas e de mútuas fertilizações.

A escola contemporânea, visível nos dias de hoje, não se concebe sem amarração nos contextos locais e existenciais, aí onde se desenrolam as vidas das pessoas, com os seus problemas, é certo, mas também com os seus sonhos e as suas aspirações. A escola de hoje procura, por isso mesmo, apresentar-se e constituir-se como mais relacional, mais contextual, mais comunitária, mais embutida nas espacialidades dos atores sociais. Sua legitimidade advém da infusão no meio, da implicação na vida das pessoas e da preparação dos alunos para viverem, como pessoas e como cidadãos, nesse meio, dando-lhes uma 
formação global ou integral, feita de competências sociais, éticas, cívicas e políticas, além das académicas e instrumentais, já que a escola não se pode eximir da capacitação que tanto permite escalar patamares escolares como pode abrir caminho à inserção profissional.

Ou seja, o que está a acontecer é a afirmação de uma escola de corpo inteiro, de instrução e de educação, como já se vislumbra em leis de bases e em planos nacionais de educação, onde tanto se faz a aprendizagem da complexidade de ser cidadão e, portanto, de ser ator social com as diversas sensibilidades (democrática, social, solidária, igualitária, intercultural, ambiental) em que hoje se materializa essa condição (IMBERNÓN, 2014, p. 51), como se faz a aprendizagem de uma futura profissão, ou a descoberta de uma vocação, de uma inclinação, de percursos possíveis no enredo dos universos profissionais em mutação.

A escola que assim se afirma no panorama contemporâneo, porque renasce como instituição socioeducativa no meio da fluidez e da incerteza, ou em "tempos líquidos", como diria Bauman (2007), tem o desiderato de ser efetivamente pragmática, mas sem deixar de pensar muito bem na melhor maneira de capacitar os alunos para viverem nos seus contextos, sendo atores sociais críticos e interventivos na melhoria desses contextos, designadamente no que concerne a materialização dos valores e dos direitos que protegem a dignidade humana de todos, sem discriminações de raça, classe, sexo, género, credo, etnia ou religião. Essa capacitação é tanto mais relevante quanto os alunos, imersos em contextos de profundas desigualdades e indignidades, absolutamente contrárias ao espírito mais genuinamente democrático, as experienciam quotidianamente.

O presente e o futuro da escola é cada vez mais ético, social e político, e os professores, agentes educativos e sociais, veem-se na contingência, e também na necessidade, de repensar o que é ser professor nesses cenários. O nosso tempo, no que respeita à escola, configura uma nova forma de ser professor, uma vez que o professor "tem de participar ativa e criticamente no seu contexto e transmitir aos futuros cidadãos valores e formas de comportamento democrático, igualitário, respeitador da diversidade cultural e social e do meio ambiente" (IMBERNÓN, 2014, p.52). As suas funções extravasam claramente o âmbito da sala de aula e dão uma outra intencionalidade ao que se passa na aula. É de um outro profissionalismo do que se trata: não o profissionalismo gerencialista, relacionado com imperativos ligados a uma maior prestação de contas e com questões de eficiência e eficácia, típico das diretivas políticas que querem impor uma 
agenda de performatividade ao nível do ensino, mas um profissionalismo democrático onde

[...] o professor surge com responsabilidades mais amplas, para além da sala de aula, incluindo o contributo para a escola, para o sistema educativo, para a comunidade e para os alunos, bem como responsabilidades coletivas enquanto profissão, com vista à construção de uma sociedade mais justa e democrática (FLORES, 2014, p. 860).

assente em direitos e em padrões de bem- estar individual e social amplamente partilhados por todas as camadas da população, sem exceções, sem discriminações.

Os critérios a que se remete a profissão, no âmbito desse profissionalismo emergente, não são tanto a concentração nos valores da instrução e da gestão desse processo em função de padrões impostos top down, ou desde as esferas que tutelam o sistema de ensino, mas a dedicação a valores e a ideais de sociedade inclusiva, equitativa e de iguais oportunidades, numa assunção da indiscutível "politicidade da educação" (FREIRE, 1996, p. 70) enquanto decorrem as interações educativas com os alunos, os pais, os encarregados de educação e bem assim com os stakeholders da envolvência da escola que participam desse processo de múltiplas dimensões, de múltiplas faces e de múltiplos rostos.

Dessa forma, configura-se e ganha expressão, não necessariamente com a mesma intensidade em todos os lugares de enraizamento, mas seguramente com os mesmos ingredientes e com a mesma motivação, uma significativa modificação da profissionalidade docente, podendo entender-se esta profissionalidade, em termos genéricos, como "aquilo que é específico na ação docente, isto é, o conjunto de comportamentos, conhecimentos, destrezas, atitudes e valores que constituem a especificidade de ser professor" (MORGADO, 2011, p. 798), ou seja, e convergindo com a nossa linha argumentativa, aquilo que define as características essenciais do novo modo de ser e de se compreender professor na escola do mundo contemporâneo, seja em termos de conhecimentos disciplinares ou académicos, seja sobretudo em termos de predisposições, valores, adesões e opções político-pedagógicas.

A profissionalidade dos docentes, apesar das resistências e das dores de parto, e mais por força das reconfigurações da escola do que em virtude das injunções ministeriais (DUBET, DURU-BELLAT, 2015, p. 46), entrou num processo de mudança que está para durar. Muda a escola e por arrastamento, a profissionalidade do professor, porque essa instituição é interpelada no sentido de assumir uma função mais social e educativa, 
querendo isso dizer, hoje em dia, que deve desenvolver uma ação mais em sintonia com os requerimentos da sociedade e dos próprios alunos, requerimentos que têm a ver, em não pouca medida, com as aspirações de democracia e de democratização de todas as esferas onde se dão interações humanas significativas, como a esfera das relações entre pais e filhos e entre cônjuges (espaço doméstico), a esfera das relações sociais entre os cidadãos e o Estado (espaço da cidadania), ou ainda, e para só ficar pelas mais próximas, segundo Sousa Santos (2013, p. 226), a esfera das relações laborais ou do processo de trabalho.

A profissão docente, nesse contexto de afirmação de outras orientações e de outros valores, está efetivamente mudando, embora o foco da mudança, por razões que se prendem com a "cultura da performatividade" (OSBORN, 2006, p. 252), esteja momentaneamente colocado no lado errado: na lamentável pressão sobre o desempenho dos professores em termos de resultados, de burocracia ou, mais exatamente, "hiperburocracia" (LIMA, 2015, p. 1347), de prestação de contas, de "accountability" (AFONSO, 2012, p. 472), e de escrutínio crítico segundo padrões meramente contabilísticos.

$\mathrm{O}$ que seria de esperar, face às tendências mais profundas que temos vindo a evidenciar, é que a pressão ajudasse a consumar o novo modo de estar na profissão, condicionando o docente a ser um agente de educação social, preocupado com os valores democráticos e com o destino social dos alunos. Uma pressão desse tipo também ajudaria a criar, na classe dos docentes, a necessidade da reinvenção ou reconceitualização das suas identidades profissionais, doravante colocadas na situação, e perante o desafio, de capacitarem os alunos para viverem em consonância com os valores mais apreciados nos espaços estruturais sociais, tornando-se agentes sociais críticos e sujeitos interventivos na materialização desses valores. Pode-se perguntar, pois, se essa reinvenção ou reconceitualização da identidade dos docentes passa pela noção de empoderamento e se a prática do empoderamento seria a forma mais ajustada de dar impulso a essa mudança.

\section{RECONCEITUALIZAÇÃO DA IDENTIDADE DO PROFESSOR DESDE O REFERENCIAL DO EMPODERAMENTO}

Quando se argumenta que estão reunidas as condições, e se torna urgente, reconceitualizar ou reinventar a identidade dos docentes, isto é, "a imagem que têm de si próprios, os sentidos que atribuem ao seu trabalho e a si próprios enquanto professores e os 
significados que os outros lhes atribuem" (FLORES, 2014, p. 853), não se está a querer dizer que basta um novo look ou uma simples operação de cosmética para deixar tudo na mesma. Essa é uma estratégia "lampedusiana" ou "gatopardista", certamente interessante de seguir no romance Il Gattopardo de Giuseppe Tomasi di Lampedusa, mas pouco recomendada para os professores que diariamente fazem a experiência da relativa inadequação entre o que realmente fazem, e que lhes dá uma certa identidade, além de algum conforto e de alguma segurança, e o que realmente se espera deles, especialmente nos contextos onde as questões sociais da democracia e dos direitos mais desafiam a escola a investir na formação de cidadãos aptos a compreenderem criticamente o mundo à sua volta e eventualmente intervirem na sua modificação ou, pelo menos, a estarem apetrechados das capacidades, e da autoestima, que possibilitarão, quando for caso disso, o envolvimento ativo em dinâmicas de transformação estrutural dos cenários sociais mais próximos.

O que realmente se espera dos professores, nessas situações ou nessas circunstâncias, que de excecional pouco ou nada têm, mesmo nos países com democracias consolidadas e com Estados socialmente generosos, é que revalorizem de vez a dimensão educativa do seu trabalho e não tanto, como tem acontecido, a tarefa instrutiva, isto é, de distribuição de saberes ou conhecimentos, tarefa ou função hoje cada vez mais disseminada na "sociedade em rede" (CASTELLS, 2007) e, portanto, cada vez mais protagonizada por outras instâncias que não a escola. Assim, importa incorporar, no registo da identidade profissional dos professores, a ideia, crescentemente inevitável, que a educação não é o "trabalho sujo" do professor, trabalho "que sempre teríamos de delegar ou remeter para outros" (DUBET, DURU-BELLAT, 2015, p. 85), como de facto é defendido por quem quer esvaziar de significado social, ético e político a profissão docente, mas um trabalho da maior importância ou relevância, ou não se desse o caso de contribuir, desde tenra idade, para o despertar dessa "vocação ontológica de intervir no mundo" de que nos fala Paulo Freire em Pedagogia da Autonomia (1996, p. 54), e que pode ser decisiva para colocar mais justiça no mundo, nos contextos onde crianças, jovens e adultos aspiram a "Ser Mais".

Uma definição mais completa do trabalho do professor e, portanto, da sua identidade, passa hoje em dia por abrir espaço à educação e à vida coletiva, melhor, à educação que se religa à vida coletiva e nela encontra o seu húmus e a sua razão de ser. Uma abertura que implica tomar em mãos a personalização e a cidadanização dos alunos, capacitando-os, não 
apenas para o respeito das normas e convenções vigentes, mas também, e eventualmente, para o questionamento do pensamento mainstream, se eivado de ideologias que, naturalizando as desigualdades e as discriminações, amesquinham o ser humano e o seu direito a ser mais.

De uma ou de outra forma, tudo isso remete para o empoderamento dos alunos, não importa com que faixa etária trabalha o professor, e para a reconsideração da identidade dos docentes, já que não se afigura realista manter a imagem de uma atividade que manifestamente muda de signo ou registo, ainda que não implique, como defendemos, a saída da sua disciplina ou a rutura com a cena pedagógica da sala de aula.

O empoderamento, enquanto processo e enquanto resultado, dá uma outra intencionalidade ao trabalho do professor e é suficientemente heurístico para redefinir, em tempos de novas exigências, a sua identidade. Mas o que é o empoderamento? Estamos perante uma noção incontroversa, de significado unanimemente partilhado?

O bom acolhimento da noção de empoderamento em diferentes áreas e em diversas disciplinas, como a educação, a intervenção comunitária, o serviço social, a saúde pública, a psicologia social ou mesmo o management, assim como a ampla mobilização dessa noção por agências internacionais de ajuda ao desenvolvimento, entre as quais o Banco Mundial (2002), parecem sugerir que estamos perante um vocábulo consensual, objeto da maior concordância quanto ao seu significado. É certamente uma evidência, amplamente comprovada, que o empoderamento se tornou, sobretudo a partir dos anos 1990, uma buzzword, isto é, uma palavra atrativa, sedutora e muito popular, mas isso não quer dizer, pelo menos até ao presente momento, que se chegou a uma visão uniforme quanto às principais articulações do seu significado. O que se verifica, pelo contrário, é a profusão de definições a seu respeito, mesmo em textos onde não seria suposto encontrar versões desencontradas, como os documentos das agências internacionais que assumem o empoderamento como fundamento, eixo de referência e imagem de marca (CALVÉS, 2009, p. 743) das suas iniciativas, dos seus projetos e dos seus programas.

A ausência de consensualidades em torno do empoderamento é uma realidade, ou não se tratasse de um conceito normativo e de carácter sociopolítico, sobressaturado de valores quanto à pessoa e quanto à sociedade. O empoderamento (do inglês empowerment) não é política nem axiologicamente neutro, podendo significar, mais além da ideia de acréscimo de poder enquanto processo e enquanto resultado, diferentes entendimentos desse processo e desse resultado. À luz de Bacqué e Biewener (2013), e ressignificando 
algum do vocabulário empregue por essas investigadoras, podemos delinear três possíveis entendimentos de empoderamento: o empoderamento democrático radical e integral, presente nas organizações, nos atores e nos movimentos que o assumem como aquisição de poder, ou poderes, visando a emancipação e a transformação social do entorno segundo uma lógica de aprofundamento dos princípios e valores democráticos; o empoderamento social-liberal, característico do pensamento e das práticas de reforma do Estado social; o empoderamento neoliberal, por fim, se se levar em linha de conta o empoderamento que se filia nas formas mais ou menos requintadas de governamentalidade neoliberal.

$\mathrm{Na}$ perspetiva do primeiro entendimento, e só para focar o essencial, o empoderamento é simultaneamente um processo individual e coletivo cuja meta ou objetivo é ajudar os sujeitos a conduzirem as suas vidas e também a emanciparem-se, sendo importante, na esteira das teorias de transformação social de Paulo Freire e de alguns ramos do movimento feminista, a realização de um processo ou dinâmica de conscientização enquanto parte dos processos de intervenção nas diferentes esferas de interação social. Assente numa consciência da opressão social, das assimetrias e desigualdades na distribuição do poder e dos recursos, esta visão de empoderamento, iminentemente democrática, e também multidimensional ou integral, visa permitir aos indivíduos e aos grupos aumentar o seu poder de agir e bem assim o desenvolvimento de competências que os tornem influentes nas tomadas de decisões que afetam as suas vidas. Aqui, não só se reforça a consciência crítica das situações, do mundo vivido, como se potencia o engajamento social e político na transformação desse mundo.

O empoderamento com esse tipo de posicionamento face aos atores sociais, quando assumido na sua integralidade, articula três dimensões: a dimensão individual ou interior, designando o processo que permite a cada indivíduo desenvolver uma consciência crítica e a sua capacidade de agir, implicando, por esse facto, a construção de uma imagem positiva de si, a aquisição de conhecimentos, cultura e competências que favoreçam o aprofundamento da compreensão crítica do meio, e bem assim o desenvolvimento do pensamento estratégico, tanto para alcançar objetivos pessoais, como sobretudo para atingir realizações coletivas; a dimensão interpessoal, organizacional ou coletiva, designando o desenvolvimento da capacidade de agir em colaboração ou cooperativamente no espaço público sobre pessoas e recursos; enfim, a dimensão política ou social, a qual coloca a questão da transformação da sociedade, especialmente quando é necessário 
modificar esquemas de poder, e situações geradoras de injustiças, que não se podem atribuir à inépcia, à irresponsabilidade ou à culpa dos indivíduos.

Correspondendo a visões reformistas quer da democracia, quer da regulação e da gestão de bens públicos, e inspirando-se naquilo que pode ser designado como «liberalismo igualitário», o empoderamento social-liberal só se distingue do anterior pelo facto de ser mais reservado do ponto de vista político. Este segundo entendimento de empoderamento valoriza certamente o reforço dos poderes do sujeito, genericamente considerado, como o poder de fazer escolhas múltiplas e o poder de fazer opções de vida, porém, não chega a questionar as dimensões estruturais das injustiças e das desigualdades que comprometem, seguramente, muitas oportunidades dos atores sociais individuais e coletivos.

A dimensão social e política do empoderamento, quando está presente, apenas é considerada, como sublinham Bacqué e Biewener (2013, p. 94), na "única perspetiva de tornar as instituições mais representativas e de estimular a reforma das políticas públicas, ajudando à construção de coligações em torno deste compromisso". Assim, mesmo que incida na capacitação do sujeito para formas mais democráticas de regulação dos bens públicos, valorizando o capital social, a responsabilidade, a inclusão, a cidadania e a participação, o empoderamento social-liberal é timorato do ponto de vista político e atenua significativamente o sentido profundo do primeiro entendimento ou visão, nomeadamente o questionamento dos diferenciais de poder que estão na base do desempowerment de pessoas singulares, coletividades e grupos organizados.

A despolitização do empoderamento, já visível na conceção social-liberal, torna-se manifesta e às claras no empoderamento neoliberal. Enquanto projeto de reforço de poderes ou capacidades (capacity building), esse empoderamento é estritamente individual. Consiste, antes de mais, em ações de responsabilização dos indivíduos, orientadas, em última instância, para o self-help, ou seja, para o cuidado e o socorro de si mesmo. O empoderamento, em tal caso, remete para indivíduos que devem tratar de si mesmos: espera-se que os indivíduos, reforçados na sua capacidade de agir, se insiram sem pestanejar, no mundo do trabalho e no universo do consumo. Estar empoderado (empowered) significa ter as capacidades de conduzir a sua vida, de ser empresário de si mesmo, fazendo as escolhas certas para aproveitar as oportunidades, não esperando ajudas da sociedade ou sequer daqueles que estão mais próximos. 
A promessa emancipadora do empoderamento, alimentada pela primeira conceção, é agora colocada ao serviço de um projeto estritamente individual cujo foco é o aumento das vantagens do indivíduo e do seu bem-estar material, mesmo que isso implique deixar os outros para trás. O poder, constituindo a raiz incontornável do empoderamento, remete tão só para a liberdade individual, a livre escolha e as oportunidades individuais. A questão da emancipação individual e da transformação social, sinal distintivo do primeiro entendimento de empoderamento, não surge como relevante e necessária. O que verdadeiramente importa é empoderar cada sujeito, cada individualidade, cada «átomo social», para que possa ganhar as batalhas entre pares pela disputa de recursos, vantagens, posições e consequentemente de lugares nas estruturas sociais existentes.

Como resulta desta breve exposição, o empoderamento é um conceito polissémico, cuja semântica deve ser manejada com cautela, tanto mais se estiver em causa a reconceitualização da identidade do professor a partir dele e tomando-o como eixo de referência. Se é verdade, como defendemos, que o empoderamento abre caminho a uma nova gramática de ser professor na escola dos nossos dias, escola que recebe a injunção de não se alhear dos problemas sociais, como a insustentável leveza da democracia e a negação de direitos em certos contextos, não seria sensato, e muito menos adequado ignorar que o que se pede à escola e ao professor não se compagina com qualquer entendimento de empoderamento, sobretudo se está em causa a capacitação dos alunos para serem agentes ativos na defesa da democracia e dos direitos mais elementares da pessoa humana.

O empoderamento dos alunos não pode ser unilateral, como no entendimento neoliberal dessa noção, nem politicamente timorato, como no empoderamento socialliberal. Só um empoderamento radicalmente democrático e multidimensional, contemplando aspetos individuais, sociais e políticos, e acreditando na mudança das estruturas existentes, pode efetivamente cumprir com o desiderato da cidadanização democrática dos alunos e com a sua transformação, desde a mais tenra idade, em atores sociais comprometidos com a construção de uma sociedade em que a democracia não seja letra morta e os direitos mero flatus vocis, isto é, pura retórica bem pensante, meras palavras, ainda que atrativas.

A opção, por parte do professor, por essa modalidade de empoderamento, não se deixará de colocar, seja no período da formação inicial e da entrada na carreira, seja durante a trajetória profissional e a formação contínua. O professor, em questões de 
empoderamento, é chamado a uma definição, pois, como nos diz Paulo Freire, "Não posso ser professor a favor de quem quer que seja e a favor de não importa o quê” (1996, p. 102). E essa definição não é apenas por uma questão de respeito aos alunos, como também alerta Freire (p. 71), mas essencialmente por uma questão de coerência com o novo propósito do ensino: empoderar para dar oportunidade aos alunos de serem cidadãos de corpo inteiro nos seus contextos de vida, aficionados pelos direitos e amantes da democracia.

Uma vez assumido como sinal distintivo da sua ação no seio da escola e, em particular, enquanto se dedica à sua disciplina curricular, o empoderamento de amplo espectro desafia o professor a investir diferentes áreas de intervenção. Que áreas seriam essas?

\section{EMPODERAMENTO ESCOLAR: ÁREAS DE INTERVENÇÃO DO PROFESSOR}

O professor, podendo agora ser considerado um profissional do empoderamento, desse empoderamento que dá robustez ao sentido ético, social e político do seu trabalho, não tem que sair da sua zona de conforto e, portanto, da sua disciplina, para cumprir com a função de fortalecimento dos poderes do aluno em compreender o mundo, em se compreender a si mesmo e em intervir no mundo para o moldar aos valores e aos direitos que tornam "a sociedade menos feia e menos arestosa" (FREIRE, 1996, p. 42), porque mais conforme às aspirações das pessoas a uma vida decente e digna. Será suficiente, e não mais do que isso, dar uma outra intencionalidade ao que faz com os alunos e para os alunos, investindo em determinadas áreas de empoderamento, tendo sempre em conta o que melhor contribui para a emergência de sujeitos sociais críticos e atores socialmente comprometidos com a melhoria dos seus contextos.

A essa luz, destacam-se três importantes áreas de empoderamento: o empoderamento cognitivo, de carácter essencialmente epistémico; o empoderamento psicológico, mais centrado na intimidade dos sujeitos, na imaginação e na força das convicções; e, por fim, o empoderamento político, precisamente aquele que as versões sociais-liberais e, sobretudo, neoliberais de empoderamento desconsideram, e que se centra em questões tão básicas como a capacidade de argumentação de posições próprias e o reforço, quando não a ativação, da capacidade de participação enquanto dimensão da cidadania ativa. 
Ao reforço do quadro epistémico do aluno e, portanto, da capacidade que o torna possível, cabe chamar empoderamento cognitivo. Este empoderamento, em contexto de sala de aula, desenvolve-se em várias frentes: antes de mais, e sempre a partir da "leitura de mundo com que o educando chega à escola" (FREIRE, 1996, p. 122), consiste em ativar e reforçar a compreensão crítica da realidade social na forma de um exercício de conscientização que aprofunda a tomada de consciência do mundo e dos obstáculos que se levantam à sua transformação. As crianças e os jovens querem compreender o mundo (MARTUCCELLI, 2016, p. 170), e não devem ser os docentes a impedir que isso aconteça. Pelo contrário, convém alimentar esse desejo com conhecimentos da sua disciplina e introduzir, sendo necessário, pensamento divergente acerca da realidade social habitada pelos alunos. Desse modo, criam-se condições para desafiar o senso comum dominante e os "significados que estruturam a ordem social" (VICH, 2013, p. 130), nomeadamente os que naturalizam as assimetrias de poder e legitimam discriminações e desigualdades.

O reforço do quadro epistémico do aluno e, portanto, o seu empoderamento cognitivo, também passa pela "aprendizagem das relações de poder, seja entre adulto e alunos ou entre iguais" (IMBERNÓN, 2014, p. 82) e pela tomada de consciência progressiva de que o poder está presente em discursos e que estes não são mais do que redes de significados que condicionam e orientam as pessoas no dia a dia. Será uma aquisição importante para o aluno aprender que o "poder produz discursos e que esses discursos são técnicas de saber embutidas nos costumes e nas práticas sociais" (VICH, 2013, p. 133). Igualmente significativo para o aluno é o desenvolvimento e/ou fortalecimento das competências de reflexão e de problematização das situações sociais que fazem parte do seu quotidiano, o que, segundo Leite e Fernandes (2010, p. 51), se pode conseguir com "a participação dos educadores e dos educandos em reflexões sobre os valores presentes na sociedade e nas diversas atuações". É dever da escola (e do professor) "falar com os alunos acerca do que os preocupa no dia a dia" (DUBET, DURU-BELLAT, 1015, p. 73), ou seja, abrirem-se às suas preocupações existenciais e, sobre esse chão, desencadear processos dialógicos que aprofundem e consolidem o poder reflexivo de crianças e jovens, poder que se articula com a emergência de leituras críticas da realidade.

O empoderamento cognitivo do aluno engloba, ainda, alargar o conhecimento de direitos, nomeadamente os que protegem da discriminação, e a aquisição de novos conhecimentos que permitam, ou venham a permitir, reinterpretar as suas relações com o 
mundo, abrindo novas vias de interação com ele, rompendo silêncios e afirmando posições, mesmo contra o pensamento mainstream a que se moldam as pessoas. E como as crianças e os jovens, estudantes nas escolas do século XXI, vivem numa «sociedade em rede», importaria que o seu empoderamento ajudasse a tomar consciência que "o poder é multidimensional e é organizado através de redes, programadas em cada domínio de atividade humana de acordo com os interesses e valores dos atores com poder" (CASTELLS, 2013, p. 25). Assim, cria-se a oportunidade para se perceber, obviamente com linguagem adaptada a cada faixa etária, que as redes de comunicação hoje massivamente utilizadas pelos educandos são importantes fontes de poder e que essas redes, essencialmente do mundo dos ecrãs, aspiram a controlar as suas mentes com verdades convenientes, ou a manietá-los com ardis discursivos, quando a eles se dirigem para vender produtos ou oferecer ajuda.

A esse empoderamento de cariz intelectual, perfeitamente ao alcance do professor nos processos de ensino-aprendizagem, acrescenta-se o "empoderamento psicológico" (RAPPAPORT, 1984; ZIMMERMAN, 2000) como segunda área de intervenção. Mesmo sem ser um perito em psicologia, ou possuir credenciais nesse domínio, o professor, no espaço educativo da sala de aula, pode ser um agente ao serviço do empoderamento psicológico dos alunos e cumprir com o grande objetivo desse empoderamento: reforçar a crença do sujeito em si mesmo e aumentar a sua autoestima e a sua autoconfiança por forma a acreditar que, apesar das dificuldades e dos obstáculos, por vezes difíceis de transpor nas situações reais, é possível imaginar futuros alternativos e agir em conformidade, tanto para introduzir melhorias na sua vida como para aperfeiçoar a sociedade existente. Como diz Paulo Freire, “mudar é difícil, mas é possível” (1996, p. 44).

O empoderamento psicológico, não dependendo apenas do professor nem se realizando somente na sala de aula, também se insere na atividade docente. O professor pode ser decisivo a esse respeito, influenciando positivamente a autoestima e a autoconfiança do aluno pelo modo como interage com ele, como o ajuda a superar obstáculos de aprendizagem curricular, como valoriza as pequenas conquistas (small wins) do dia a dia, como lhe dá feedback positivo quando está por baixo, e como reforça a sua assertividade, isto é, a capacidade de afirmar posições, defender valores e reivindicar direitos. Seja como for, e a investigação até oferece outras técnicas que podem ser úteis ao professor (POZO, 2014, p. 30), o essencial joga-se no sucesso escolar do aluno e no apoio que pode ser dado a esse objetivo. O sucesso nas aprendizagens é o melhor afrodisíaco do 
empoderamento psicológico, da elevação da autoestima e do reforço da autoconfiança. Com sucesso, o aluno desenvolve a perceção de competência, melhora a autoimagem e acredita, ou começa a acreditar, que pode ser útil na resolução de problemas que afetam a sua vida, a família e a sociedade. A esta luz, e sobre essa base de autoconfiança e de autoestima, o empoderamento político, enquanto terceira área de intervenção do professor, torna-se mais realista e capaz de acontecer no espaço pedagógico das atividades curriculares.

A precoce ideologização dos educandos, sobretudo se forem crianças, ou qualquer forma insidiosa de doutrinação política, não é certamente o que se pede ao professor quando se aponta a necessidade de intervir no empoderamento político dos públicos escolares. Mal estaríamos se essa área de empoderamento redundasse em formas mais ou menos requintadas de instrumentalização das consciências, fazendo da sala de aula um espaço para comícios e pregações laicas ao serviço de tendências políticas presentes na sociedade. É verdade que na escola, por mais que nos queiram convencer do contrário, não há lugar para práticas apolíticas (FREIRE, 1996, p. 98), mas também não é sítio para preleções partidárias e inculcações de credos políticos. Os professores, possuidores de uma ética profissional equilibrada e sensata, construída em contacto com a experiência e alicerçada nos princípios mais consagrados do respeito pelas convicções das pessoas, não enveredam por esse caminho, embora nem sempre deem a devida atenção ao empoderamento político dos alunos nos termos que pode ser realizado na escola e na sala de aula.

Com jovens e com crianças, e tirando partido, quer da mediação do acesso ao conhecimento, quer das práticas participativas no seio da instituição escolar, o empoderamento político pode passar pela potenciação de várias capacidades: antes de mais, a capacidade de análise do meio social em termos políticos, chamando a atenção para o carácter político (quer dizer, fruto de uma decisão) dos mais variados aspetos da vida social, dessa vida em que estão mergulhados os alunos. Através de pequenos passos, e trazendo a vida social para a cena pedagógica da sala de aula, pode o professor reforçar essa capacidade de análise e assim contribuir, desde a tenra idade, para uma politização dos problemas que afetam os alunos e que só têm solução onde são criados, isto é, na sociedade. Também eles têm de aprender, porque são parte interessada e porque serão os adultos de amanhã, que já não há "soluções biográficas para problemas sistémicos" 
(BECK; BECK-GERNSHEIM, 2003, p. 31), ou seja, "soluções individuais para problemas socialmente produzidos" (BAUMAN, 2009, p. 109).

Outra das capacidades a potenciar, ou a desenvolver/reforçar, é a capacidade de argumentação. Todas as disciplinas têm algo a oferecer nesta matéria já que todas intersetam temas sociais polémicos e dignos de discussão. É pela discussão que se potencia a capacidade de argumentação, ou seja, a defesa de posições esclarecidas e fundamentadas, mesmo que o objetivo não seja, como lembra Martuccelli (2016, p. 169), "que cada um se converta num perito em todas as áreas, disciplinas e matérias". As opiniões até podem ser importantes, mas o essencial joga-se na aprendizagem do debate e da racionalidade que o deve atravessar. Assim, o professor, todos os professores, no âmbito das suas disciplinas, preparam os alunos para a argumentação crítica e, portanto, para o fortalecimento de um poder ou capacidade que será bastante útil para o exercício da cidadania.

O empoderamento político dos educandos em idade escolar, e que se encontram na escola, ficaria incompleto, para não dizer truncado e seriamente comprometido, se não integrasse, em lugar de destaque, o desenvolvimento da capacidade de participação nos assuntos comuns, dando-se assim expressão ou realização a essa "vocação ontológica de intervir no mundo" (FREIRE, 1996, p. 54) que mora em cada aluno, ainda que in statu nascendi e à espera de fortalecimento. É aos poucos que as crianças e os jovens aprendem a influir nas decisões que afetam as suas trajetórias vitais nos espaços estruturais sociais, e não da noite para o dia. A escola e, em particular, a sala de aula, reúnem condições para se fortalecer essa capacidade, mas é preciso envolver os educandos na tomada de decisões. Os alunos a nosso cargo, a cargo dos professores, não precisam apenas de ser ouvidos ou escutados. Também precisam de ser envolvidos nas deliberações a seu respeito. Só assim começarão a acreditar nas virtudes da democracia e a julgar que vale a pena como sistema de vida.

Cada docente, no marco dos seus objetivos curriculares, pode ser um agente de empoderamento, e isso dá um outro alcance, e provavelmente um outro élan, à sua profissionalidade. Em torno desta nova profissionalidade desenha-se uma identidade que só tem vantagens em se afirmar, quanto mais não seja para dar relevância social ao trabalho do professor e, espera-se, um outro reconhecimento, especialmente nos contextos que mais requerem uma escola educativa e social, comprometida com uma formação de qualidade, abrangendo necessariamente a capacitação do cidadão. 


\section{CONSIDERAÇÕES FINAIS}

A mera transmissão de saberes disciplinares, ainda que realizada com certificação académica de nível superior, não se perfila mais como o âmago da profissão docente. Não é dessa forma que o professor vai ajudar a escola a cumprir com a função social que hoje se espera dela e a capacitar os alunos para um mundo que os coloca cada vez mais em dificuldades e lhes lança permanentes desafios em termos de inclusão social. Os alunos precisam de ser empoderados para poderem enfrentar esse mundo e defenderem os valores que a todos protegem da indignidade, vale dizer, dos estados de natureza que amesquinham o ser humano.

Os professores têm de se convencer que se espera mais deles, tal como da escola, e que esse plus pode muito bem ser o empoderamento dos alunos, empoderamento que não implica renegar a nobre missão de mediar o acesso ao conhecimento e à cultura, e muito menos abandonar o espaço educativo da sala de aula.

O que quisemos defender é que o empoderamento, dizendo respeito a todos os docentes, e dando dimensão ética, social e política à sua profissão, vai em contramão do estreitamento da sua função à mera tarefa instrutiva e à implementação de práticas que pouco contribuem para a melhoria da qualidade do ensino e da aprendizagem. A reconceitualização da identidade do professor em torno do empoderamento leva a resistir a esse estreitamento e coloca-se evidentemente do lado da elevação dos padrões de qualidade da formação escolar. Os baixos níveis de status dos professores, em alguns contextos, não servem de desculpa à rejeição, ou simplesmente à desconsideração do empoderamento dos alunos. O empoderamento das jovens gerações está na ordem do dia, seja nos Objetivos de Desenvolvimento Sustentável aprovados pela Nações Unidas em setembro de 2015, seja mais regionalmente na «Nova Estratégia para os Jovens Europeus 2010-2018», intitulada: Investing and empowering. Claro que ninguém pode empoderar se não estiver empoderado. Sendo assim, é preciso assegurar, através de formação inicial e contínua, o empoderamento dos professores. Talvez seja isso o que se quer dizer, no ponto 9 da Declaração de Incheon (elaborada por alturas do Fórum Mundial de Educação 2015), quando solenemente se proclama: «Garantiremos que professores e educadores sejam empoderados». Serão as autoridades responsáveis pela formação dos docentes capazes de assumir esse desafio e de passar sem demora das palavras aos atos? 


\section{REFERÊNCIAS}

AFONSO, Almerindo. Para uma concetualização alternativa de “accountability” em educação. Educação \& Sociedade, Campinas, v. 33, n. 119, p. 471-484, abr./jun. 2012.

BACQUÉ, Marie.-Hélène; BIEWENER, Carol. L'empowerment: une pratique émancipatrice. Paris: La Découverte, 2013.

BANCO MUNDIAL. Empowerment and poverty reduction: a sourcebook. Washington: The World Bank, 2002.

BAUMAN, Zygmunt. El arte de la vida. Barcelona: Paidós, 2009.

BECK, Ulrich; GERNSHEIM, Elisabeth. La individualización. El individualismo institucionalizado y sus consecuencias sociales y políticas. Barcelona: Paidós, 2003.

CALVÉS, Anne-Emmanuèle. "Empowerment": généalogie d'un concept clé du discours contemporain sur le développement. Revue Tiers Monde, Paris, v. 4, n. 200, p. 735-749, out./dez. 2009.

CASTELLS, Manuel. A sociedade em rede. Lisboa: Fundação Calouste Gulbenkian, 2007.

CASTELLS, Manuel. Redes de indignação e esperança. Movimentos sociais na era da Internet. Lisboa: Fundação Calouste Gulbenkian, 2013.

CASTILLO, Miquel; BRETONES, Eva. Acción social y educativa en contextos escolares. Barcelona: UOC, 2014.

DUBET, François; DURU-BELLAT, Marie. 10 propositions pour changer d'école. Paris: Seuil, 2015.

FLORES, Maria Assunção. Discursos do profissionalismo docente. Paradoxos e alternativas conceptuais. Revista Brasileira de Educação, Rio de Janeiro, v. 19, n. 59, p. 851-869, out./dez. 2014.

FREIRE, Paulo. Pedagogia da autonomia: saberes necessários à prática educativa. São Paulo: Paz e Terra, 1996.

IMBERNÓN, Francisco. Calidad de la enseñanza y formación del profesorado: un cambio necesario. Barcelona: Octaedro, 2014.

LEITE, Carlinda; FERNANDES, Preciosa. Desafios aos professors na construção de mudanças educacionais e curriculares: que possibilidades e constrangimentos? Educação, Porto Alegre, v. 33, n. 3, p. 198-204, set/dez. 2010.

LIMA, Licínio. A avaliação institucional como instrumento de racionalização e o retorno à escola como organização formal. Educação e Pesquisa, São Paulo, v. 41, no especial, p. 1339-1352, dez. 2015. 
MARTUCCELLI, Danilo. Condición adolescente y ciudadanía escolar. Educação \& Realidade, Porto Alegre, v. 41, n. 1, p. 155-174, jan./mar. 2016

MORGADO, José Carlos. Identidade e profissionalidade docente: sentidos e (im)possibilidades. Ensaio, Rio de Janeiro, v. 19, n. 73, p. 793-812, out./dez. 2011.

NAÇÕES UNIDAS (2015). Objetivos de Desenvolvimento Sustentável. Disponível em: http://www.itamaraty.gov.br/images/ed_desenvsust/ODSportugues12fev2016.pdf.

OSBORN, Marilyn. Changing the context of teacher's work and professional development: a European perspective. International Journal of Educational Research, New York, v. 45, p. 242-253, 2006.

POZO, Maria José. A autoestima: teoria e prática. In: GONZÁLEZ-PÉREZ, Joaquim; POZO, Maria José (Eds.). Educar para a não-violência. Perspetivas e estratégias de intervenção. Lisboa: Bookout, 2014. p. 18-48.

RAPPAPORT, Julian. Studies in empowerment: introduction to the issue. In: RAPPAPORT, Julian; HESS, Robert (Dir.). Studies in empowerment. Steps toward understanding and action. New York: Haworth Press, 1984. p. 1-8.

SOUSA SANTOS, Boaventura. Pela mão de Alice: o social e o político na pósmodernidade. Coimbra: Almedina, 2013.

UNESCO. Declaração de Incheon, 2015. Disponível em: http://unesdoc.unesco.org/images/0023/002331/233137POR.pdf.

VICH, Víctor. Desculturalizar la cultura. Latin American Research Review, PittsburgPennsylvania, v. 48, Special Issue, p. 129-139, dez. 2013.

ZIMMERMAN, Marc. Empowerment theory: psychology, organizational and community levels of analysis. In: RAPPAPORT, Julian; SEIDMAN, Edward (Eds.). Handbook of community psychology. New York: Kluwer/Plenum Publishers, 2000. p. 43-63.

Data de recebimento: $16 / 09 / 2016$

Data de aceite: $24 / 10 / 2017$ 